\title{
Expansion of Tubular with Elastomers in Multilateral Wells
}

\author{
Md Veldena and FKS Al-Jahwari*b \\ ${ }^{a}$ Senior Well Engineer, Concept \& Design, Shell Oil, Seria, Brunei \\ ${ }^{b}$ Mechanical Engineering Department, University of Toronto, Canada
}

Received 29 January 2012; accepted 30 September 2012

\begin{abstract}
The use of solid expandable tubular technology during the last decade has focused on solving many challenges in well drilling and delivery including zonal isolation, deep drilling, conservation of hole sizes, etc. not only as pioneered solution but also providing cost effective and long lasting solutions. Concurrently, the technology was extended for construction of multilateral in typical wells. The process of horizontal tubular expansion is similar to the vertical expansion of expandable tubular in down-hole environment with the addition of uniformly distributed force due to its weight. The expansion is targeted to increase its diameter such that post expansion characteristics remain within allowable limits. In this study a typical expandable tubular of $57.15 \mathrm{~mm}$ outer diameter and $6.35 \mathrm{~mm}$ wall thickness was used with two different elastomer seals of 5 and $7 \mathrm{~mm}$ thickness placed at equal spacing of $200 \mathrm{~mm}$. The developed stress contours during expansion process clearly showed the high stress areas in the vicinity of expansion region which lies around the mandrel. These high stresses may result in excessive wear of the mandrel. It was also found out that the drawing force increases as the mandrel angle, expansion ratio, and friction coefficient increases. A mandrel angle of $20^{\circ}$ requires minimum expansion force and can be considered as an optimum geometrical parameter to lower the power required for expansion.
\end{abstract}

Keywords: Multilateral well, Horizontal expansion, Finite element analysis, Oil well, Tubular

$$
\begin{aligned}
& \text { تمديد الأنابيب المزودة باللدائن في الآبار المتعددة الأطراف } \\
& \text { مارك د فيلدن أو فاروق خ س الجهوري بـ }
\end{aligned}
$$

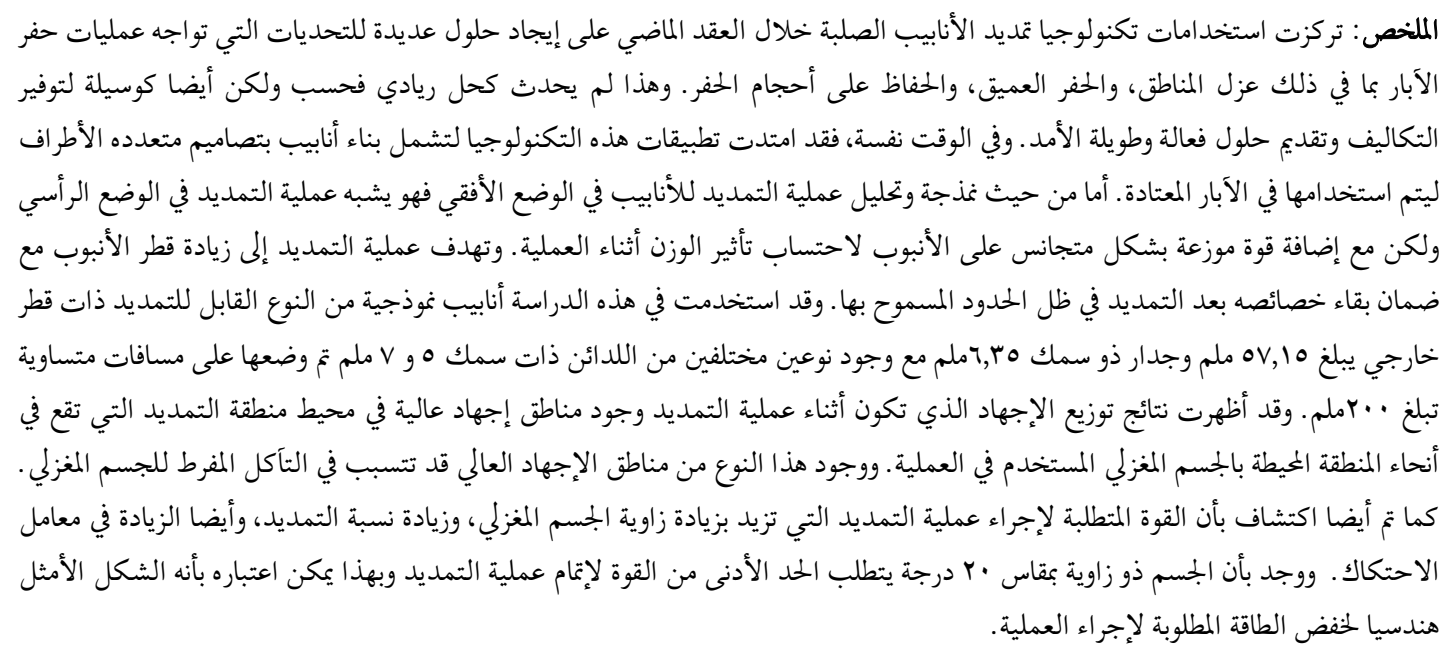

المفردات المفتاحية: الآبار المتعددة الأطراف، التمديد الأفقي، التحليل بطريقة العنصر المحدود، آبار النفط، الأنابيب.

*Corresponding author's e-mail: farooq@mi.utoronto.ca 


\section{Introduction}

The core issue in developing the solid expandable systems is to reduce installation risks, while driving down construction and well repair costs and minimizing drilling hazards. Solid tubular expansion technology is essentially a down-hole cold working process of a solid steel tubular aiming to increase its diameter with the mean of a hardened mandrel through the use of pressurized fluid or mandrel on stick approach. In both cases the effective internal forces must not exceed the allowable tubular strength with the provision of reasonable safety limit. The expansion process subjects the solid tubular to a large plastic deformation leading to variations in tubular thickness and length, which may result in premature and unexpected failures. Research work in expandable tubular technology started to provide solutions for many problems such as zonal isolation, deep drilling, conservation of hole sizes, etc. (Stewart et al. 1999; Daigle et al. 2000; Owoeye et al. 2000). There is no doubt that the most significant benefit of expandable tubular technology is its enabling capacity to drill deeper, and reach hard to access and small scattered pockets of reservoirs. It had been proven that the technology can be extended to accomplish multilateral wells using special arrangement at the branching point from the main borehole (Zhang et al. 2009).

For a number of years, the industry has sought to use single diameter expandable liner extensions as an alternative to conventional casing designs. A single diameter expandable liner extension enables the drilling of deeper exploration and production wells with larger hole sizes. A solid expandable system developed in collaboration between Baker Oil Tools and British Petroleum allows for the isolation of reactive shale zones, subsalt environments, low-fracturegradient formations or other drilling situations without reducing the casing and subsequent drilled-hole size into the reservoir (Coolkidge et al. 2007). Weatherford (2009) has successfully designed and developed another variant of tubular technology called Metal Skin system. The system was developed to tackle four main functions. These include: 1) open-hole liner; 2) mono-bore open-hole liner; 3) cased-hole liner; and 4) mono-bore open-hole clad. Most of these systems can be used for multiple applications, to address both pre-planned and remedial well construction challenges. However, there are slight differences in the problems targeted by the individual system versions. Another operator has developed one of its fields using open-hole, multi-lateral completions in longreach horizontal wells. Water production problems and the inability to re-enter open-hole sidetracks led to the use of solid expandable tubular and intelligent well technology to control the wells. The horizontal well was transformed into a tri-lateral forked well.

Binggui et al. (2009) developed a finite element model sing a commercial finite element analysis software to analyze the stress, strain, and residual stress in an expandable tubular without elastomers and applied it in casing repair of damaged wells, as well as to monitor the changes on internal surfaces of the tubular. However, their model simulates expansion of vertical tubular without the inclusion of weight effect. Akhtar et al. (2012) compared different elastomer material model when used with expandable tubular for expansion. They developed a suitable hyper-elastic material model for elastomer by best fitting the tensile behavior of the elastomers commonly used with expandable tubular. The experiments were conducted on exposed elastomers and the experimental data was then fitted to Neo-Hookean model to be used for finite element simulations.

The numerical simulation of expandable tubular in horizontal wells for a combined tubular-elastomer system was not investigated by many researchers due to the complexity at tubular/mandrel/formation contact surfaces. Pervez et al. $(2007 ; 2005)$ simulated the expansion of tubular with elastomers for both horizontal and vertical cases. The results were summarized with findings of significance and relevance to field engineers. It was found that the drawing force increases with an increase in mandrel angle, expansion ratio, and friction coefficients at interfaces. Tubular wall thickness decreases as the mandrel angle, expansion ratio, and friction coefficient increase. Tubular length often shortens with a reduction in thickness to compensate the increase in its diameter and maintain the conservation of mass. This paper presents an extension to this study with more insight to the control parameters of the expansion process, and visualization and better understanding of stress variations at tubular/mandrel interface.

\section{Finite Element Modeling}

The horizontal tubular expansion with elastomer seals had been modeled in ABAQUS, commercial finite element analysis software, using explicit solver that adequately accounts for the nonlinearity in the system. Figure 1 shows a cross-sectional view of the tubular-elastomer geometric model. Figure 2 shows 3 $\mathrm{D}$ representation as was developed in finite element model. It consists of the tubular surrounded by 200 $\mathrm{mm}$ long elastomer seal of either 5 or $7 \mathrm{~mm}$ thickness. The elastomer seals are placed in cascades with a gap of $200 \mathrm{~mm}$. The tubular is $1500-\mathrm{mm}$ long and has an 


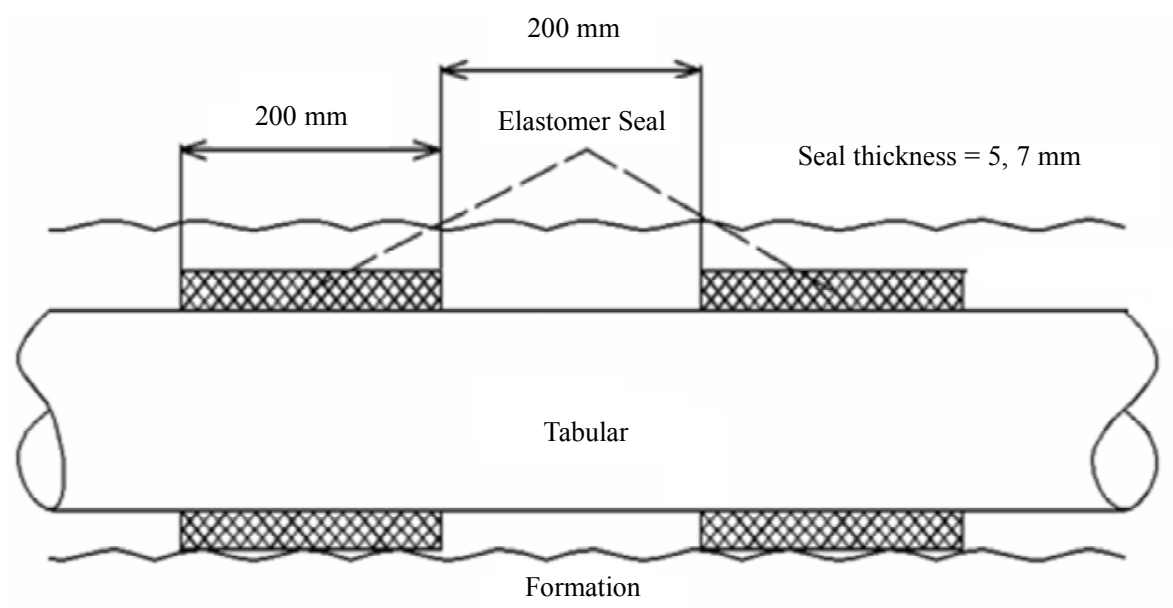

Figure 1. Cross-sectional view of horizontal tabular with seals and formation

Table 1. Values of parameters used in simulation of horizontal solid tabular expansion

\begin{tabular}{lcc}
\hline$\#$ & Parameter & V alues \\
\hline 1 & Mandrel angle (degrees) & $10,20,45$ \\
2 & Expansion ratio (\%) & $15,17,20,22$ \\
3 & Tubular/mandrel friction coefficient & $0.1,0.2,0.3,0.4$ \\
4 & Seal thickness (mm) & $5.0,7.0$ \\
5 & Seal/formation friction coefficient & $0.1,0.2,0.3,0.4$ \\
\hline
\end{tabular}

inner diameter and thickness of $57.15 \mathrm{~mm}$ and 6.35 $\mathrm{mm}$, respectively. Tubular expansion was achieved by pushing an analytical rigid mandrel through the tubular by prescribed mandrel displacement in the software.

Formation was modeled as analytical rigid body which implies that the surrounding medium is rocklike material. Seals were assumed to be perfectly bonded to the tubular ie. no relative motion between seal and tubular is allowed while the interaction takes place between mandrel, tubular and formation. The contact conditions at these interfaces were modeled using Coulomb friction law. Linear brick finite element having 8-nodes per element with reduced integration was used for the whole system with optimized mesh size and reasonably enough through-thickness elements to account for the tubular-seal elongation at the expense of reduction in cross-sectional area of each. Due to the symmetry only one half of the tubular was considered while the axi-symmetric approximation was excluded because of gravitational effects. Three different mandrel angles of 10, 20 and 45 degrees were used to study the effect on expansion behavior. For each of these mandrel angles, the parameters of interest such as expansion ratio, seal thickness and friction coefficients were varied to see their effect on expansion process. Different expansion ratios were governed by the tubular diameter after expansion. Table 1 shows a summary of the parameters used in this study and their corresponding values. For field needs, effects on the drawing force, length and thick- ness of the tubular were investigated by varying the friction coefficients at the tubular-mandrel and sealformation interfaces, mandrel angle (geometrical factor that significantly affect the expansion process), seal thickness, and expansion ratio.

\section{Material Model}

Tubular was modeled as an elastic-plastic material obeying the power hardening law due to the large plastic deformation resulting from the expansion process. Typical steel data was used with modulus of elasticity $\mathrm{E}=200 \mathrm{GPa}$, Poisson's ratio $v=0.3$, material yield strength $\mathrm{S}_{\mathrm{y}}=500 \mathrm{MPa}$, and hardening parameter $\mathrm{n}=$ 0.25 . Subsequently, actual stress-strain data obtained through experiment was used to investigate similar problems under realistic conditions.

The elastomer seal was considered as a non-linear elastic material due to high compression ratios. Elastomeric material of the seal was modeled using Arruda-Boyce model in ABAQUS. In general, an elastomer is very flexible for tensile and shear loading, but extremely stiff for hydrostatic deformations. Arruda-Boyce model parameters were obtained by the ABAQUS built-in curve fitting procedure using experimental nominal stress vs. nominal strain data. The stability of the solution is achieved by carefully selecting the step sizes in ABAQUS. However, Neo-Hookean model would be more accurate as suggested by Akhtar et al. (2012) but may not necessarily yield a numerically stable model. 


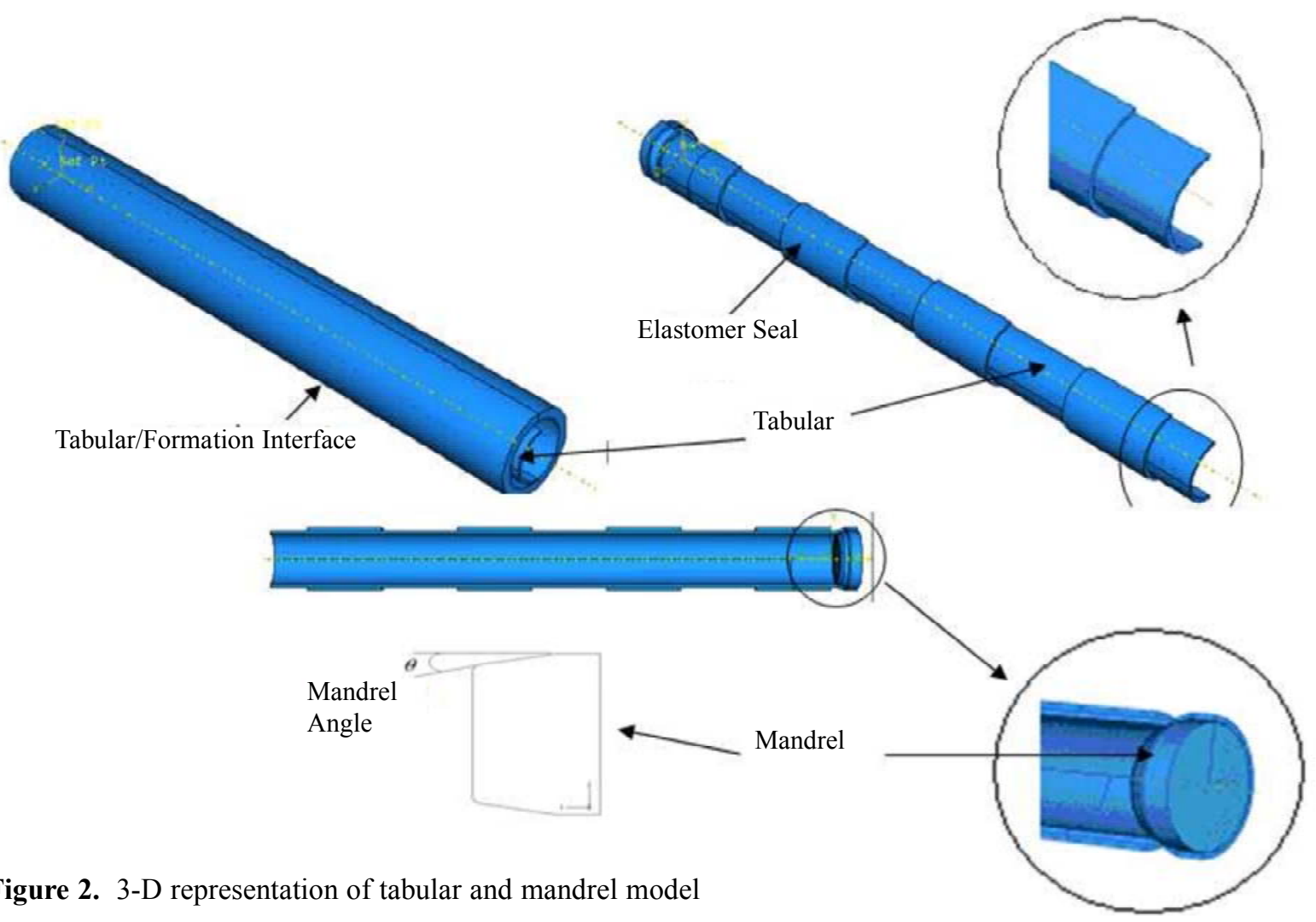

\section{Boundary and Loading Conditions}

Due to symmetry all nodes lying on the plane of symmetry were constrained in the direction perpendicular to the plane. In addition, the left end of the tubular was held fixed hence the tubular expands under tension. The right end of the tubular was free to move. The mandrel moved from left to right at a constant low speed of $1.5 \mathrm{~m} / \mathrm{min}$. This was achieved by defining a reference node at the center of the mandrel which followed a pre-defined path during expansion process. Due to low mandrel speed, the strain rate effect was assumed to be negligible. All six degrees of freedom for the reference node of the formation were fixed. The mandrel was also constrained from rotation about its own axis. The gravity force was applied on the tubular and mandrel, and assumed negligible for seals. This was due to much smaller weight of seals compared to the tubular.

\section{Results and Discussions}

Results type and representation were carefully selected to support the requirements of field engineers. These results can be of importance in decision making by well engineers at the start and during expansion process. The important expansion parameter studied in this paper is the expansion or drawing force. Geometrical and contact factors affecting it are also investigated. Figure 3 shows the stress contours of effective stresses for four different expansion ratios, for coefficient of friction $\mu=0.1$ and mandrel angle $\alpha$ $=10^{\circ}$. Although the stress contours look similar indicating that the expanded zone reaches yielding in all cases, the tubular thickness variation changes with the expansion ratio and becomes thinner as the expansion ratio increases to $22 \%$ as was also concluded by Pervez et al. (2007). The stress contour patterns for 5 or $7 \mathrm{~mm}$ thick seals look similar but differ in values. The drawing force required for $7 \mathrm{~mm}$ thick seal is higher than $5 \mathrm{~mm}$ thick seal. Figures 4 and 5 show the axial, radial, shear, and effective stress contours for various tubular expansion ratios and indicate that the stresses vary along the tubular thickness and length. Stresses concentrate in the mandrel middle section forming a ring. This indicates the possibility of mandrel/tubular wear due to high friction at interfaces.

Three important operational parameters that affect the force required for expansion are investigated. Those parameters are expansion ratio, friction coefficient, and the mandrel angle. The expansion ratio is selected as per the production well requirements and conditions. However, friction coefficient is always aimed to be minimized within a reasonable cost limit but the mandrel angle may be optimized without significant economical affect. The drawing force increases with the friction coefficient and expansion ratio irrespective of mandrel angle as shown in Fig. 6. It is interesting to note that the variation in expansion force 
Expansion of Tubular with Elastomers in Multilateral Wells
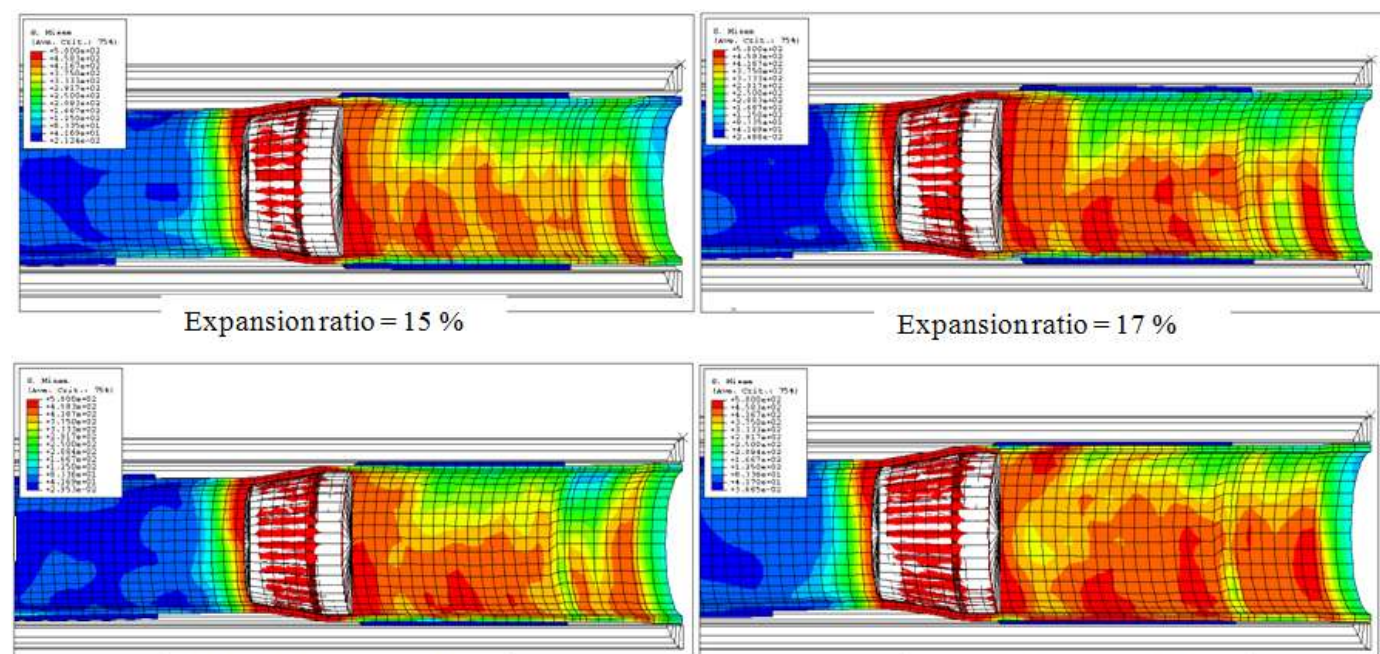

Expansionratio $=20 \%$

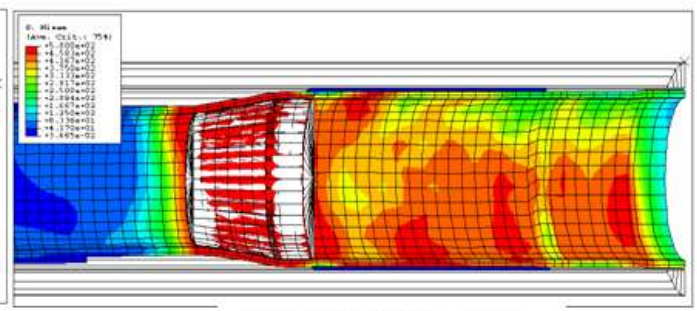

Expansion ratio $=22 \%$

Figure 3. Effective stress contours for $\mu=0.1$ and $\alpha=10^{\circ}$
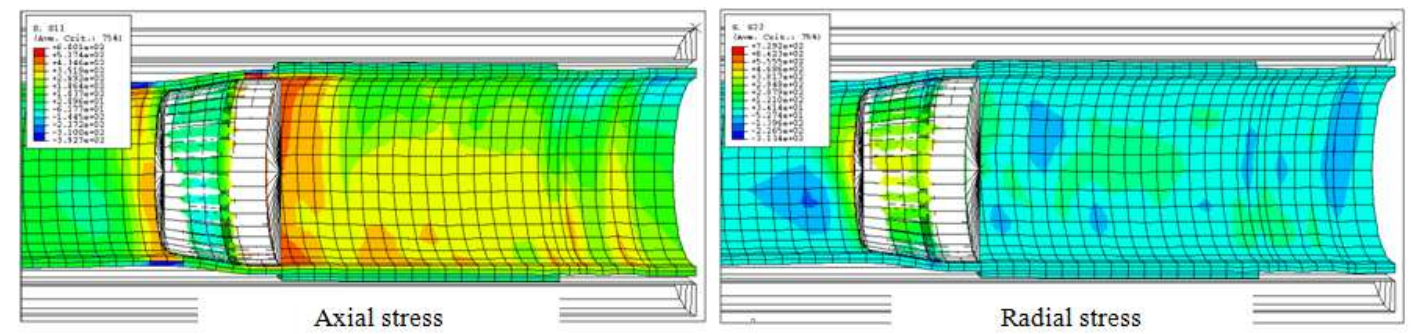

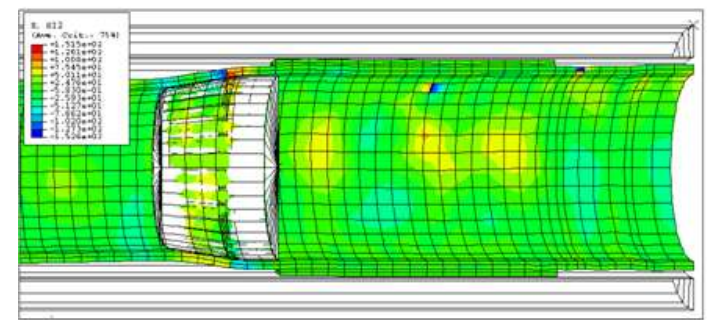

Shear stress

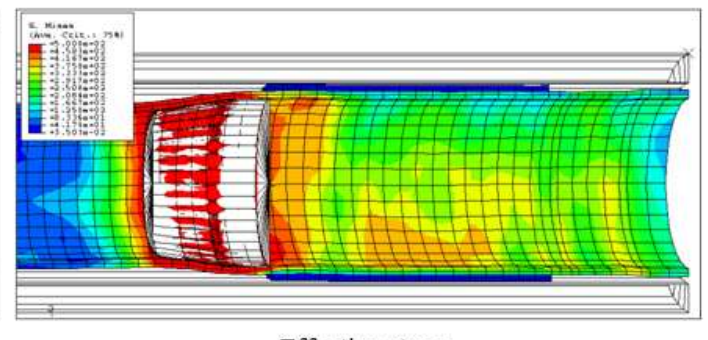

Effective stress

Figure 4. Plot of stress contours for $\mu=0.2, \alpha=10$ for $15 \%$ expansion ratio

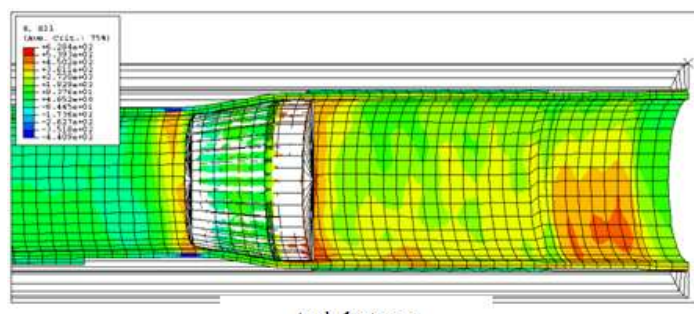

Axial stress

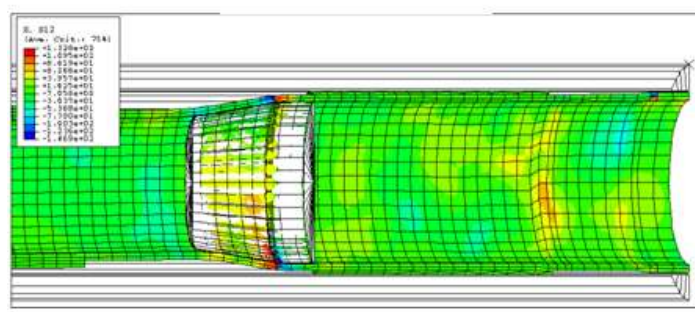

Shear stress

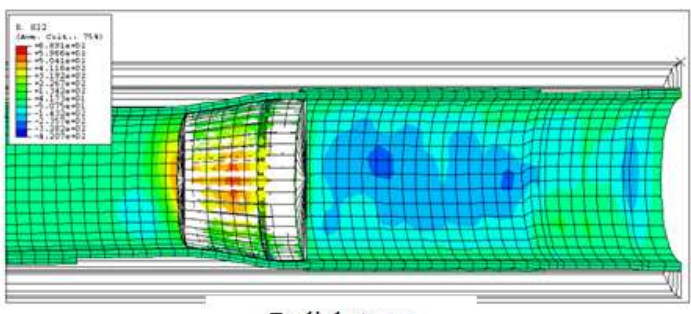

Radial stress

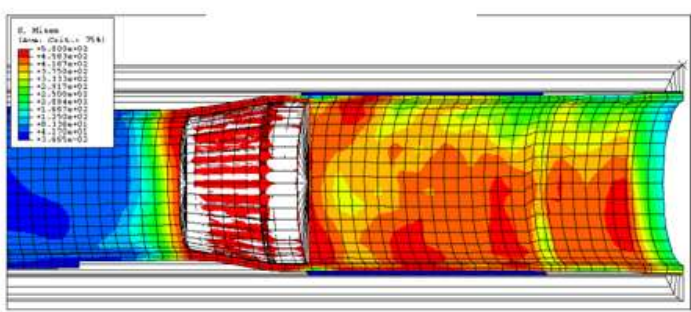

Effective stress

Figure 5. Plot of stress contours for $\mu=0.2, \alpha=10$ and $22 \%$ expansion ratio 

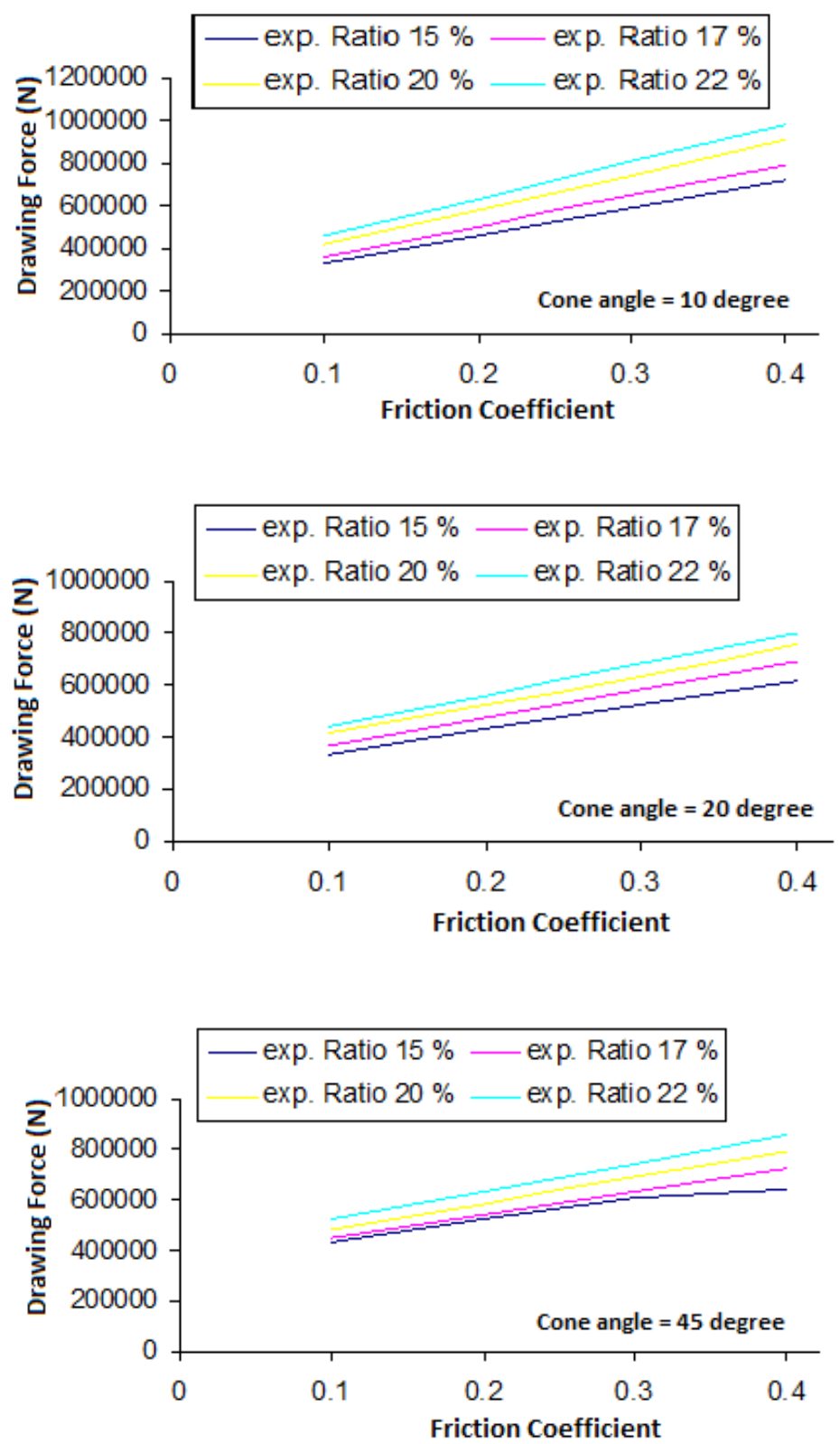

Figure 6. Variation in drawing forces w.r.f friction coefficient for different expansion ratios

becomes very small for $15 \%$ expansion ratio when the value of coefficient of friction increases to 0.3 or more. This suggests that low cost coating has to be used on tubular internal surfaces when the mandrel is 45 degree and desired maximum expansion ratio is $15 \%$ or less. Figure 7 show the variation in expansion forces with respect to friction coefficient for different mandrel angle. The variation pattern is similar to that of Fig. 6 with one exception. All four figures, representing expansion ratios from $15 \%$ to $22 \%$ indicate that the best mandrel angle for lower expansion force is $20^{\circ}$.
Figure 8 shows the variation in expansion forces with respect to the mandrel angle at four different values of coefficient of friction. It is clear from the figure that the expansion force decreases as the mandrel angle increases. The lowest expansion force is attained in the vicinity of 20 degree mandrel values. The mandrel angle is not the same for all coefficients of friction and varies between 18 and 20 degrees. However, as a general guideline, the mandrel angle of 20 degree will requires less power or expansion. It reinforces the conclusion from Fig. 7. Again, at higher value of friction coefficient $(\mu=0.4)$, increase in mandrel angle beyond 
Expansion of Tubular with Elastomers in Multilateral Wells
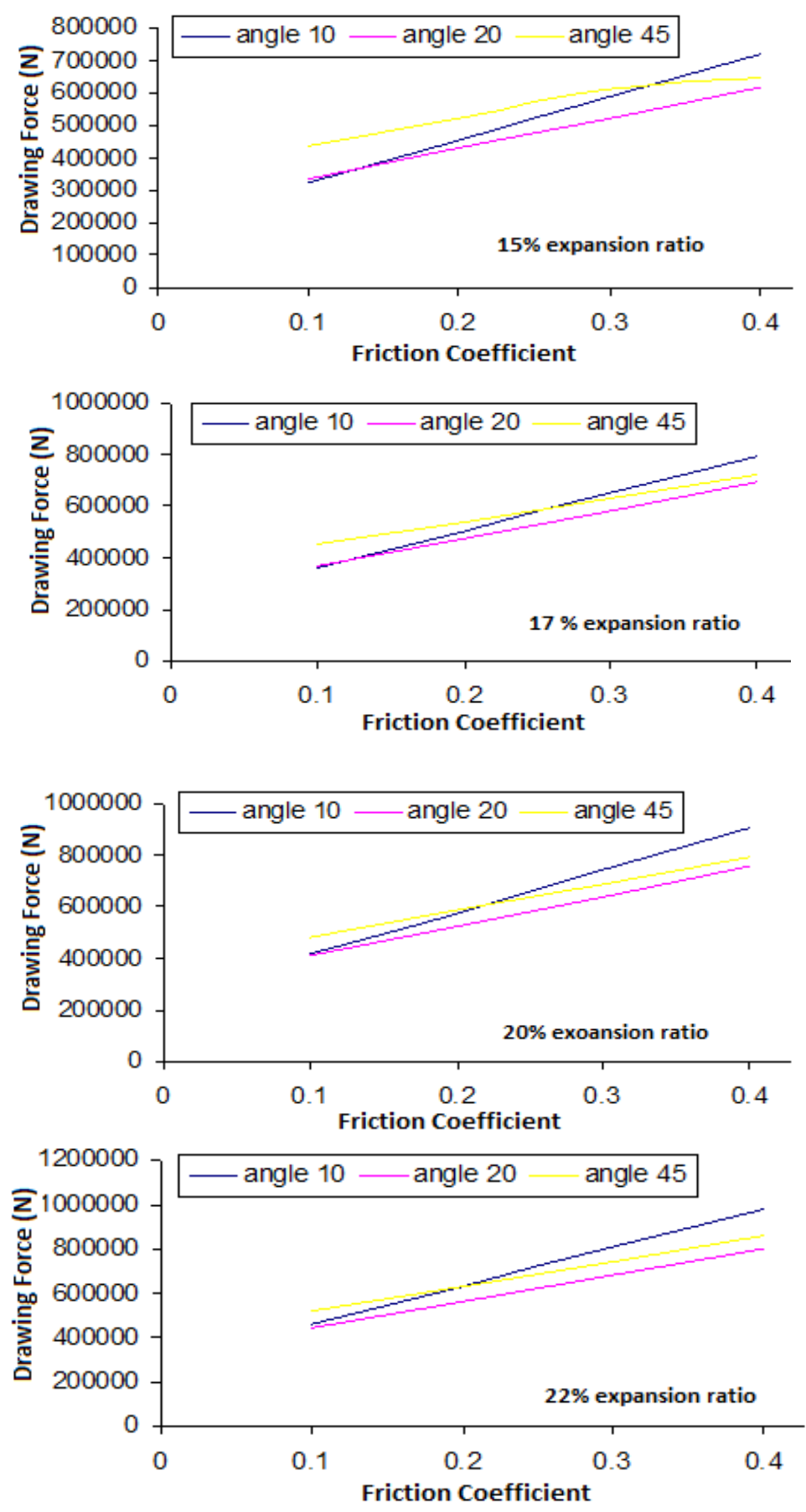

Figure 7. Variation in drawing w.r.f friction coefficient for different mandrel angles

20 degree does not alter the required expansion forces. Hence, a mandrel with 20 degree angle is desirable due to reduced manufacturing cost.

\section{Conclusions}

The simulation of solid expandable tubular, using finite element analysis, in horizontal wells for a combined tubular-elastomer system was performed for different contact conditions representing various field scenarios. The seals of $200 \mathrm{~mm}$ length and 5 or $7 \mathrm{~mm}$ thick were placed at equal intervals of $200 \mathrm{~mm}$. Stress contours showed that the expanded zone reaches yielding in all cases and form a high stress ring around the effectively expanding edge of the mandrel strengthening the view of excessive wear of mandrel. Expansion forces were found to increase as the mandrel angle, expansion ratio, and friction coefficient increase. The effect of one parameter over the other is negligible. 

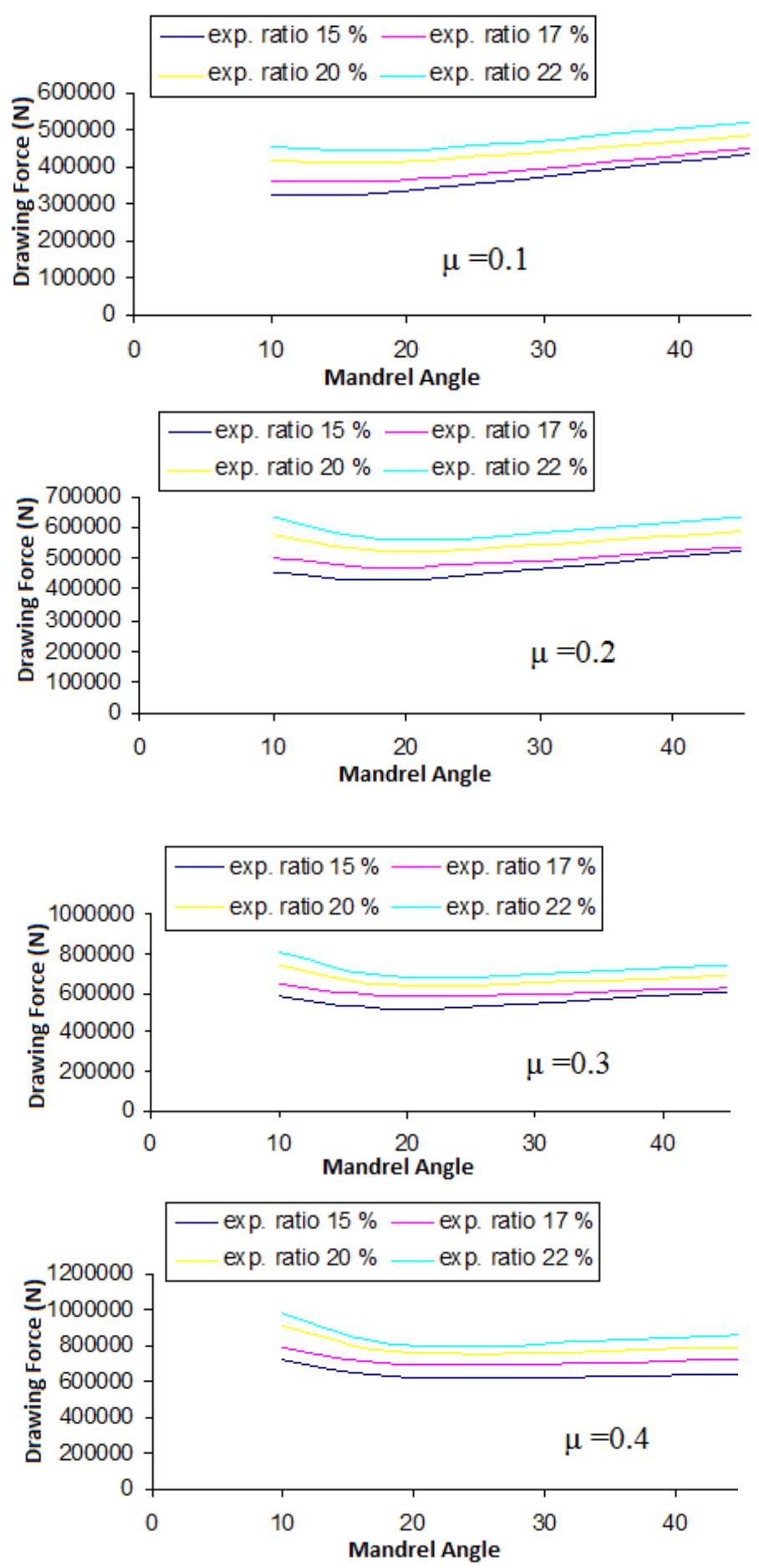

Figure 8. Variation in drawing force w.r.t the mandrel angle for various friction coefficients

\section{References}

Akhtar M, Qamar SZ, Pervez T, Khan R, Al-Kharusi MSM (2012), Elastomer seals in cold expansion of petroleum tubulars: Comparison of material models. Journal of Materials and Manufacturing Processes 27:715-720.

Binggui X, Zhang Y, Wang H, Hongwei Y, Jia T (2009), Application of numerical simulation in the solid expandable tubular repair for casing damaged wells. Journal of Petroleum Exploration and Development 36(5):651-657.

Coolidge R, Baker RV, Stockmeyer CE, Adam M, Emerson B (2007), BP, Baker run first expandable monobore liner extension system. Practical Drilling Technology Special Report, Oil and Gas Journal 12:1-5.

Daigle CL, Campo DB, Naquin CJ, Cardenas R, Ring LM, Yourk P (2000), Expandable tubulars: Field examples of application in well construction and 
Expansion of Tubular with Elastomers in Multilateral Wells

remediation. SPE paper \# 62958, SPE Annual Technical Conference and Exhibition, Dallas, Texas.

Owoeye OO, Aihevba LO, Hartmann RA, Ogoke VC (2000), Optimization of well economics by application of expandable tubular technology. IADC/SPE paper \# 59142, IADC/SPE Drilling Conference, New Orleans, Louisiana.

Pervez T, Seibi AC, Al-Hiddabi SA, Al-Jahwari FK, Qamar SZ, Marketz F (2007), Solid tubular expansion in horizontal wells. SPE paper \# 105704, 15th Middle East Oil and Gas Show and Conference, MEOS, Bahrain.

Pervez T, Seibi AC, Karrech A (2005), Simulation of solid tubular expansion in well drilling using finite element method. Journal of Petroleum Science and Technology 23:775-794.

Stewart RB, Marketz F, Lohbeck WCM (1999), Expandable wellbore tubulars. SPE paper \# 60799, SPE Technical Symposium, Dhahran, Saudi Arabia.

Weatherford Meta Skin System. 2009. http:/www.weatherford.com/ECMWEB/groups/ web/documents/weatherfordcorp/WFT098992.pdf.

Zhang Y, Rongquan R, Wang H, Wang J (2009), Multilateral drilling and completion technology based on solid expandable tubular fixing system. Journal of Petroleum Exploration and Development 36(6):768-775. 